\title{
Nutritional status of trauma patients hospitalized at surgical intensive care unit
}

\author{
Babak Hosseinzadeh Zoroufchi (1), Abolfazl Abdollahpour (1), Hamid Reza Hemmati (2)
}

(1) Department of Anesthesiology, and (2) Department of Surgery, Kowsar Hospital, Semnan University of Medical Sciences, Semnan, Iran

This article is distributed under the terms of the Creative Commons Attribution Noncommercial License (CC BY-NC 4.0) which permits any noncommercial use, distribution, and reproduction in any medium, provided the original author(s) and source are credited.

\begin{abstract}
Malnutrition results from a decrease or increase or imbalance of energy, protein and other nutrients, leading to measurable negative effects on body tissue, body shape, organ function and clinical status. Research shows that nutritional support is one of the necessary processes for survival of traumatic patient hospitalized at surgical intensive care unit. The purpose of this study is to evaluate the nutritional status of trauma patients hospitalized at surgical intensive care unit of Kowsar Hospital in Semnan, Iran. This cross-sectional descriptive study was performed on patients older than 18 years with head, neck and femur injuries. Initial data were collected using a checklist containing demographic information questions, designed from the Ministry of Health and Medical Education's Nutrition Screening Form, which was available in the Nutrition Assessment Forms and Guidelines for Hospitalized Patients Approved in 2013. The data were analyzed using Chi-square or Fisher's exact tests, paired t-test and Pearson coefficient. The confidence level was $95 \%$ and significance level was less than 0.05 in all tests. The amount of energy determined by the intensive care unit for the patients, with a significantly lower relationship than the amount of energy required by the patients for 24 hours, based on the Harris Benedict formula was $(918.20 \pm 474.80$ calories vs. $1535.76 \pm 243.73$ calories, respectively and Pvalue $<0.001)$. The amount of protein determined by the intensive care unit for the patients for 24 hours, with a significantly relationship lower than the protein required for the patients for 24 hours, was $(51.68 \pm 34.39$ vs. $106.57 \pm 13.67$, respectively, and $\mathrm{P}$-value $<0.001)$. There was a statistically significant relationship between the age of the patients and energy $(\mathrm{P}<0.001)$ and protein $(\mathrm{P}<0.001)$ determined by the intensive care unit for the patients for 24 hours and energy $(\mathrm{P}<0.001)$ and protein $(\mathrm{P}<0.001)$ required for the patients for 24 hours. The results of this study showed that both the amount of energy and the amount of protein determined by the intensive care unit for trauma patients for less than 24 hours were lower than the required level; therefore, dietary modification for these patients is recommended.
\end{abstract}

Key Words: Nutritional assessment, trauma patient, Intensive Care Unit

Eur J Transl Myol 30 (2): 311-317, 2020

Malnutrition is a state of nutrition that results from a decrease or increase or imbalance of energy, protein and other nutrients, leading to measurable negative effects on body tissue or body shape (shape, size, body composition), organ function and clinical status. ${ }^{1}$ Malnutrition is one of the most serious problems in the world, especially in hospitalized patients. Malnutrition has detrimental effects on the treatment process of patients. ${ }^{2}$ The importance of nutrition at hospital units cannot be ignored. This importance is particularly emphasized at intensive care units, as malnutrition is a major problem in many hospitals, especially at intensive care units. ${ }^{3,4}$ Studies have shown that the prevalence of malnutrition among adults in all age groups ranges from 20 to $69 \%,{ }^{5}$ and has a high prevalence of $40 \%$ among patients hospitalized at intensive care units. Over 35\% of patients hospitalized at intensive care units were malnourished at the time of admission, ${ }^{6}$ and about two thirds of the patients experience poor nutritional status during hospital stay. Malnutrition can increase risks of infection, spread stress ulcers, reduce wound healing, prolong hospital stay, increase health care costs, and increase morbidity and mortality. ${ }^{7}$ Therefore, supportive nutrition is an essential component of treatment for such patients. ${ }^{8}$ Research shows that nutritional support is one of the supportive processes necessary for the survival of 
trauma patients hospitalized at surgical intensive care units and is estimated based on the requirements met for each patient, taking into account clinical findings. ${ }^{9,10}$ During the stay in the surgical intensive care unit, malnutrition can progress with progression of disease that may be associated with reduced appetite or inability to swallow, and in some cases lack of proper function of the gastrointestinal tract and ultimately incomplete absorption of food as well as increased patient need for food due to the body's metabolic response to stress, malnutrition can progress. ${ }^{11}$ The aim of this study was to evaluate the nutritional status of trauma patients hospitalized at the intensive care units.

\section{Materials and Methods}

\section{Trial}

This descriptive cross-sectional study was performed on patients over 18 years of age with head, neck and femur injuries in the second to fourth quarters of 2016 at the surgical intensive care unit of Kowsar Hospital in Semnan, Iran. Inclusion and exclusion criteria are listed in Table 1. In this study, 40 trauma patients aged 18 years or older with head, neck and femur injuries were selected by simple or available sampling method. Initial data were collected using a checklist containing questions about demographic information, clinical examination, and paraclinical information collected and were followed up. In other words, the data collection was based on a

Table 1. Inclusion and exclusion criteria

\section{Inclusion criteria}

1. Being 18 years old and over

2. Consent of the patients or the caregivers for participation in the study

3. No need for emergency or sequential surgeries

4. Trauma patients with head, neck and femur injuries

5. Patients without any underlying disease

6. Patients who only had enteral and parenteral nutrition and who did not have oral nutrition

\section{Exclusion criteria}

1. Infection or other disease during the study

2. Certain underlying disease such as diabetes requiring special diets

3. Unexpected reactions and discharge or death of the patients before completing the data collection process

4. Failure to measure one of the anthropometric or biochemical or nutritional evaluation markers

5. Pregnancy and lactation

6. Liver and renal patients

7. Lack of consent to participate in the study researcher-made questionnaire developed from a portion of the Ministry of Health and Medical Education's Nutrition Screening Form that was available in the Nutrition Assessment Forms and Guidelines for Hospitalized Patients Approved in 2013, including patients' demographic information, disease records, biographies, clinical examinations, anthropometric evaluations, nutrition type, and nutritional pathways. The first part of the checklist contained demographic information (sex, age, and body temperature), medical history and clinical examination of physicians, which was completed based on the patient records in the ward. A mercury thermometer was used to determine patients' body temperature. The thermometer was placed in the axillary region of the patient and precisely on the skin, and the patient arm was attached to the trunk. Just one thermometer was used for all patients to prevent measurement error. A non-elastic tape measure with a 5 $\mathrm{mm}$ accuracy, based on which the height of the subjects was measured, was used to measure the length of the ulna (distance of the ulnar elbow bulge to the prominent point of the wrist) in $\mathrm{cm}$. It should be noted that in order to reduce the error, measurements of height and body temperature and other anthropometric markers of the patients were performed by one person. In the second part, the data from the results obtained during the study were collected and recorded. Assessment of dietary intake of each patient, including type of nutrition and amount of energy received, was determined by calculating the amount of calories received from enteral and parenteral or oral nutrition and the amount of administration. Patients' protein and energy intake status was calculated based on their nutritional times and the amount of protein and energy in each type of material used. In the case of foods prepared by the caregivers or outside the hospital and the patients consumed them, the patients were under complete control in terms of their calorie intake. If the food was consumed out of the researcher's control, the research unit would be excluded from the study. The energy required by the patients were calculated and obtained using the Harris-Benedict formula. 55 to $65 \%$ of this was for carbohydrates, 25 to $30 \%$ for fat and 15 to $20 \%$ for protein. Therefore, the protein needed by the patients at the intensive care unit was considered to be 1 to $1.5 \mathrm{~kg} / \mathrm{kg}$ for ideal weight. Since micronutrients are important to consider and increasing or decreasing laboratory markers such as serum albumin, phosphorus, magnesium and total lymphocyte count may be indicative of poor nutritional status of patients; therefore, laboratory values of albumin, potassium, total lymphocyte count, sodium, phosphorus and magnesium were recorded as biochemical markers. These biomarkers were measured in the hospital's medical diagnostic laboratory. This study examined only energy and protein and did not address the critical micronutrients needed for these patients, such as selenium and zinc, because the cost of examining these micronutrients was beyond the budget of the project. 


\section{Nutritional status of trauma patients}

Eur J Transl Myol 30 (2): 311-317, 2020

\section{Sample size}

The sample size of this study was 388 people based on the formula below, based on the Krishnan et al. (2002) study, which reported an average intake of $52 \%$, and 40 were collected during the study period: ${ }^{12}$

$$
\mathrm{N}=\frac{Z_{1-\frac{a}{2}}^{2} \mathrm{P}(1-\mathrm{P})}{\mathrm{d}^{2}}
$$

\section{Data collection method}

Data were recorded in pre-developed forms by research colleagues and entered into SPSS version 23 for statistical analysis. Numerical variables, mean and standard deviation (Mean \pm Std.Deviation) were reported for statistical description, and for categorical variables, count and percentage were reported. Data were analyzed using chi-square or Fisher's exact tests, paired sample ttest and Pearson's coefficient. In all tests, confidence level was $95 \%$ and significance level was less than 0.05 .

\section{Ethical considerations}

In this study, the checklists were anonymous and included only raw data and figures. Research units were also assured that we were committed to protecting their information and that this information would remain confidential. On the other hand, written consent was received from all research units and they were assured that if they did not consent to continue their participation, they would have the right to withdraw at any stage of the project.

\section{Results}

According to the results of the age criterion evaluation, the mean age was $49.35 \pm 23.5$ years. The minimum age was 19 years and the maximum age was 94 years. According to the count distribution and frequency percentage of the age groups, $17(42.5 \%)$ were in the young group (19-39 years), $10(25 \%)$ were in the middleaged group (40-59 years) and $13(32.5 \%)$ were in the elderly group (60 years and older), respectively. Also 25 $(62.5 \%)$ subjects were male and $15(37.5 \%)$ were female. The mean and standard deviation of body temperature in the axillary region were 36.71 and $0.27^{\circ} \mathrm{C}$, respectively. The minimum body temperature in the axillary region of the subjects was $36^{\circ} \mathrm{C}$ and the maximum was $37.2^{\circ} \mathrm{C}$, respectively, based on which none of the subjects had fever during the study. The mean ulnar length of the subjects was $26.59 \pm 1.68 \mathrm{~cm}$. The minimum ulnar length of the subjects was $23.5 \mathrm{~cm}$ and the maximum was 29.5 $\mathrm{cm}$. The mean and standard deviation of the subjects' height were 172.17 and $7.84 \mathrm{~cm}$, respectively. The minimum height of the subjects was $153 \mathrm{~cm}$ and the maximum was $185 \mathrm{~cm}$. The mean weight of the subjects was $71.05 \pm 9.11 \mathrm{~kg}$. The minimum weight of the subjects was $53 \mathrm{~kg}$ and the maximum was $85 \mathrm{~kg}$. The mean serum lymphocyte count was $13.87 \pm 8.31$ units. The minimum serum lymphocyte count was 1.56 units and the maximum was 35.00 units. The mean and standard deviation of white blood cell count were 10.84 and 3.91 per 1000 units, respectively. The minimum white blood cell count was 3.16 per 1000 units and the maximum was 20.26 per 1000 units. The mean serum albumin concentration was $3.62 \pm 0.75$ units, respectively. The minimum serum albumin concentration was 2.50 units and the maximum was 4.50 units. The mean and standard deviation of blood sodium concentration were 139.45 and 3.76 units, respectively. The minimum serum sodium concentration was 131.0 units and the maximum was 145.0 units. The mean blood potassium concentration was $4.04 \pm 0.46$ units. The minimum serum potassium concentration was 3.10 units and the maximum was 5.20 units. The mean blood magnesium concentration was $1.57 \pm 0.2$ units. The minimum serum magnesium concentration was 1.30 units and the maximum was 1.90 units. The mean blood phosphorus concentration was $4.12 \pm 0.53$ units. The minimum serum phosphorus concentration was 3.20 units and the maximum was 4.80 units.

Also, all research units had very low levels of activity, and all research units had a history of using both intravenous feeding and nasogastric tube feeding during their recent stay at intensive care units. It should be noted that during the study no food was given to them by their caregivers. The mean and standard deviation of the number of oral or enteral feeding prescribed in the hospital at 24 hours were 7.00 and 2.68 times, respectively. The minimum number of oral or enteral feeding prescribed in the hospital at 24 hours was zero and the maximum was 8 times. Given that the caloric value of each cc of oral or enteral nutrition determined was 0.62 ; therefore, the mean and standard deviation of the caloric or enteral calorie feeding determined in the hospital within 24 hours were 843.20 and 561.05 calories, respectively. The minimum calorie of oral or enteral feeding determined in the hospital at 24 hours was zero and the maximum was 2480 calories. Also, given that the amount of protein in each cc of the oral or enteral feeding determined was 0.038 ; therefore, the mean and standard deviation of the oral or enteral protein determined in the hospital at 24 hours were 51.68 and 34.39 units, respectively. The minimum amount of oral or enteral protein, determined in hospital at 24 hours, was zero and the maximum was 152 units. The mean and standard deviation of intravenous feeding volume determined in the hospital at 24 hours were 1.36 and 0.69 liters, respectively. The minimum number of intravenous feeding prescribed in the hospital at 24 hours was one liter and the maximum was 3 liters. Normal saline serum was used in $18(45 \%)$, semi-normal serum was used in 17 (42.5\%), and $1 / 3$ and $2 / 3$ serum was used in 5 (12.5\%). The mean and standard deviation of intravenous calorie intake determined in the hospital at 24 hours were 75.00 and 200.96 calories, respectively. The minimum intravenous calorie intake determined in the hospital at 24 hours was zero and the maximum was 600 calories. 


\section{Nutritional status of trauma patients}

Eur J Transl Myol 30 (2): 311-317, 2020

\section{Analytical statistics}

Calculation of patient energy requirement for 24 hours based on the Harris-Benedict formula showed that the mean and standard deviation of patient energy requirement for 24 hours were 1535.76 and 243.73 calories, respectively. The minimum amount of energy needed for the patients for 24 hours was 1015.14 calories and the maximum was 1958.73 calories. The results of the data analysis showed that the amount of energy determined by the intensive care unit for the patients for 24 hours with a significantly less relationship than the amount of energy required for the patients for 24 hours based on the Harris-Benedict formula was (918.20 \pm 474.80 calories vs. $1535.76 \pm 243.73$ calories, respectively, and $\mathrm{P}$-value $<0.001)$. The mean and standard deviation of the amount of energy determined and required for the patients for 24 hours by different age groups are given in Table 2 . The results of data analysis showed that there was a significant relationship between the age of the patients and the amount of energy determined by the intensive care unit for 24 hours $(\mathrm{P}<0.001)$. As such, at the intensive care unit, the most amount of calories were determined for the elderly (60 years and older) (992.00 \pm 607.47 calories), while the most need for calories was in the young ones (19-39 years) (1634.73 \pm 228.82 calories). The mean and standard deviation of the amount of energy determined and required for the patients for 24 hours by gender are given in Table 3 . The results of data analysis showed that there was no statistically significant relationship between the patients' genders and the amount of energy determined by the intensive care unit for 24 hours $(\mathrm{P}=0.588)$ and the amount of energy required for the patients for 24 hours based on the Harris-Benedict formula $(\mathrm{P}=0.173)$.

Relationship between the amount of calorie determined and required and the indices examined

There was no significant relationship between the amount of energy determined by the intensive care unit for 24 hours and body temperature in axillary region $(\mathrm{P}=$ 0.730 and $R=0.056)$, ulna length $(P=0.743$ and $R=$ $0.054)$, height $(\mathrm{P}=0.899$ and $\mathrm{R}=0.021)$ and weight $(\mathrm{P}=$ 0.843 and $\mathrm{R}=0.032)$. There was a significant and direct relationship between the amount of energy required for

Table 2. Mean and standard deviation of determined and required calories for the patients by age group

\begin{tabular}{|c|c|c|c|c|}
\hline \multirow{2}{*}{ Age group } & \multicolumn{2}{|c|}{ Determined calories } & \multicolumn{2}{c|}{ Required calories } \\
\cline { 2 - 5 } & Mean & Std. deviation & Mean & Std. deviation \\
\hline Young (19 to 39 years) & 943.53 & 422.07 & 1634.73 & 228.82 \\
\hline Middle-aged (40 to 59 years) & 779.20 & 370.95 & 1587.03 & 219.70 \\
\hline Elderly (60 years and older) & 992.00 & 607.47 & 1366.90 & 200.25 \\
\hline
\end{tabular}

Table 3. Mean and standard deviation of the calorie determined and required for the patients by gender

\begin{tabular}{|c|c|c|c|c|}
\hline \multirow{2}{*}{ Gender } & \multicolumn{2}{|c|}{ Determined calories } & \multicolumn{2}{c|}{ Required calories } \\
\cline { 2 - 5 } & Mean & Std. deviation & Mean & Std. deviation \\
\hline Male & 950.72 & 514.52 & 1656.02 & 205.93 \\
\hline Female & 864.00 & 411.26 & 1335.33 & 154.69 \\
\hline
\end{tabular}

Table 4. Mean and standard deviation of the protein determined and required for the patients by age group

\begin{tabular}{|c|c|c|c|c|}
\hline Age group & \multicolumn{2}{|c|}{ Determined protein } & \multicolumn{2}{c|}{ Required protein } \\
\cline { 2 - 5 } & Mean & Std. deviation & 105.26 & 14.22 \\
\hline $\begin{array}{c}\text { Young (19 to 39 } \\
\text { years) }\end{array}$ & 49.18 & 36.26 & 110.55 & 15.12 \\
\hline $\begin{array}{c}\text { Middle-aged (40 to } \\
\text { 59 years) }\end{array}$ & 44.08 & 27.24 & 105.23 & 12.18 \\
\hline $\begin{array}{c}\text { Elderly (60 years } \\
\text { and older) }\end{array}$ & 60.80 & 37.23 & & \\
\hline
\end{tabular}

Table 5. Mean and standard deviation of the protein determined and required for the patients by gender

\begin{tabular}{|c|c|c|c|c|}
\hline \multirow{2}{*}{ Gender } & \multicolumn{2}{|c|}{ Determined protein } & \multicolumn{2}{c|}{ Required protein } \\
\cline { 2 - 5 } & Mean & Std. deviation & 115.80 & 6.93 \\
\hline Male & 55.33 & 35.07 & 91.20 & 5.73 \\
\hline Female & 27.05 & 33.50 & & $90 a n$ \\
\hline
\end{tabular}


the patients for 24 hours according to the Harris-Benedict formula and ulna length $(\mathrm{P}<0.001$ and $\mathrm{R}=0.785)$, height $(\mathrm{P}<0.001$ and $\mathrm{R}=0.877)$ and weight $(\mathrm{P}<0.001$ and $\mathrm{R}=$ $0.859)$. But this relationship was not significant with body temperature in axillary region $(\mathrm{P}=0.864$ and $\mathrm{R}=$ 0.028).

\section{Relationship between the amount of calorie determined and required and biochemical markers}

There was no significant relationship between the amount of energy determined by the intensive care unit for 24 hours and white blood cell count $(\mathrm{P}=0.118$ and $\mathrm{R}$ $=0.251)$, lymphocyte count $(\mathrm{P}=0.615$ and $\mathrm{R}=-0.082)$, albumin $(\mathrm{P}=0.790$ and $\mathrm{R}=-0.043)$, sodium $(\mathrm{P}=0.374$ and $\mathrm{R}=0.144)$, potassium $(\mathrm{P}=0.744$ and $\mathrm{R}=-0.116)$, magnesium $(\mathrm{P}=0.853$ and $\mathrm{R}=0.030)$, and phosphorus ( $\mathrm{P}=0.965$ and $\mathrm{R}=0.007)$. There was no significant relationship between the amount of energy required for the patients for 24 hours based on the Harris Benedict formula and white blood cell count $(\mathrm{P}=0.705$ and $\mathrm{R}=$ $0.062)$, lymphocyte count $(\mathrm{P}=0.782$ and $\mathrm{R}=-0.045)$, albumin $(\mathrm{P}=0.804$ and $\mathrm{R}=-0.040)$, sodium $(\mathrm{P}=0.176$ and $\mathrm{R}=-0.218)$, potassium $(\mathrm{P}=0.248$ and $\mathrm{R}=-0.178)$, magnesium $(\mathrm{P}=0.773$ and $\mathrm{R}=0.047)$ and phosphorus $(\mathrm{P}$ $=0.515$ and $\mathrm{R}=0.106)$. Calculation of patient energy requirement for 24 hours showed that the mean and standard deviation of protein required for the patients for 24 hours were 106.57 and 13.67 units, respectively. The minimum amount of protein needed for the patients for 24 hours was 79.50 and the maximum was 127.50 units. The mean and standard deviation of the protein determined for the patients for 24 hours were 51.68 and 34.39 units, respectively. The results of data analysis showed that the amount of protein determined by the intensive care unit for 24 hours with a significantly less relationship than the amount of protein required for the patients for 24 hours was $(51.68 \pm 34.39$ vs. $106.57 \pm 13.67$, respectively, and $\mathrm{P}$-value $<0.001)$.

\section{Relationship between the amount of protein determined} and required and age

The mean and standard deviation of the amount of protein determined and required for the patients for 24 hours by different age groups are given in Table 4 . The results of data analysis showed that there was a significant relationship between the age of the patients and the amount of protein determined by the intensive care unit for 24 hours $(\mathrm{P}<0.001)$ and the amount of protein required for the patients for 24 hours. As such, at the intensive care unit, the most amount of protein were determined for the elderly (60 years and older) $(60.80 \pm 37.23$ units), while the most need for protein was in the middle-aged ones (40-59 years) $(110.55 \pm 15.12$ units).

Relationship between the amount of protein determined and required and gender

The mean and standard deviation of the amount of protein determined and required for the patients for 24 hours by gender are given in Table 5 . The results of data analysis showed that there was no statistically significant relationship between the patients' genders and the amount of protein determined by the intensive care unit for 24 hours $(\mathrm{P}=0.949)$ but there was a significant relationship between gender and the amount of protein required for the patients for 24 hours $(\mathrm{P}=0.004)$, so that the men needed more protein than the women did.

Relationship between the amount of protein determined and the indices examined

There was no significant relationship between the amount of protein determined by the intensive care unit for 24 hours and body temperature in axillary region $(\mathrm{P}=$ 0.538 and $\mathrm{R}=0.100)$, ulna length $(\mathrm{P}=0.382$ and $\mathrm{R}=$ $0.142)$, height $(\mathrm{P}=0.550$ and $\mathrm{R}=0.097)$ and weight $(\mathrm{P}=$ 0.550 and $R=0.097)$. There was a significant and direct relationship between the amount of protein required for the patients for 24 hours and ulna length $(\mathrm{P}<0.001$ and $\mathrm{R}$ $=0.996)$, height $(\mathrm{P}<0.001$ and $\mathrm{R}=0.996)$ and weight $(\mathrm{P}<0.001$ and $\mathrm{R}=0.999)$. But this relationship was not significant with body temperature in axillary region $(\mathrm{P}=$ 0.579 and $\mathrm{R}=0.090$ ).

Relationship between the amount of protein determined and required and biochemical markers

There was no significant relationship between the amount of protein determined by the intensive care unit for 24 hours and white blood cell count $(\mathrm{P}=0.173$ and $\mathrm{R}$ $=0.220)$, lymphocyte count $(\mathrm{P}=0.536$ and $\mathrm{R}=-0.101)$, albumin $(\mathrm{P}=0.683$ and $\mathrm{R}=-0.067)$, sodium $(\mathrm{P}=0.687$ and $\mathrm{R}=0.066)$, potassium $(\mathrm{P}=0.52$ and $\mathrm{R}=-0.104)$, magnesium $(\mathrm{P}=0.843$ and $\mathrm{R}=0.032)$, and phosphorus $(\mathrm{P}=0.952$ and $\mathrm{R}=0.010)$. There was no significant relationship between the amount of protein required for the patients for 24 and white blood cell count $(P=0.470$ and $\mathrm{R}=0.118)$, lymphocyte count $(\mathrm{P}=0.600$ and $\mathrm{R}=-$ $0.086)$, albumin $(\mathrm{P}=0.623$ and $\mathrm{R}=-0.080)$, sodium $(\mathrm{P}=$ 0.256 and $\mathrm{R}=-0.184)$, potassium $(\mathrm{P}=0.214$ and $\mathrm{R}=-$ $0.201)$, magnesium $(P=0.704$ and $R=0.062)$ and phosphorus $(\mathrm{P}=0.407$ and $\mathrm{R}=0.135)$.

\section{Discussion}

Appropriate nutritional care for patients with acute and critical conditions hospitalized at Intensive Care Unit (ICU) plays an important and decisive role in the process of patient treatment and prevention of disease progression. ${ }^{9,13}$ Various studies have shown that nutrition counseling and the implementation of a variety of nutritional support strategies by treatment teams in hospital, and in particular intensive care units, lead to a decrease in the prevalence of malnutrition. ${ }^{14,15}$ Therefore, the aim of this study was to evaluate the nutritional status of trauma patients hospitalized at surgical ICU. The amount of energy determined by the intensive care unit for the patients for 24 hours, with a significantly lower relationship than the amount of energy required by the patients for 24 hours, based on the Harris-Benedict formula was $(918.20 \pm 474.80$ calories vs. 
$1535.76 \pm 243.73$ calories, respectively and $\mathrm{P}$ value $<0.001$ ). The amount of protein determined by the intensive care unit for the patients for 24 hours, with a significantly relationship lower than the protein required for the patients for 24 hours, was $(51.68 \pm 34.39$ vs. $106.57 \pm 13.67$, respectively, and $\mathrm{P}$-value $<0.001)$. There was a statistically significant relationship between the age of the patients and energy $(\mathrm{P}<0.001)$ and protein $(\mathrm{P}<0.001)$ determined by the intensive care unit for the patients for 24 hours and energy $(\mathrm{P}<0.001)$ and protein $(\mathrm{P}<0.001)$ required for the patients for 24 hours. In studies conducted in this field, such as the study by Wei et al. ${ }^{16}$ in 2014, all adult patients hospitalized at the intensive care unit who had undergone mechanical ventilation for at least 8 days were studied. The average daily calorie intake by patients for eight days was obtained and then the life expectancy and quality of life of the patients three and six months later were assessed. The results of their studies showed that high nutrition levels in hospitalized patients in the first weeks increase life expectancy and function recovery to three months, but do not have much effect after six months. ${ }^{16}$ In a study by Cathy Alberda et al. in 2009 in Canada, 2772 patients older than 18 years who were hospitalized for more than 72 hours at the intensive care unit and were under mechanical ventilation and were intubated within the first 48 hours of hospitalization were studied. ${ }^{17}$ The results of their study showed that increasing 1000 calories per day reduces mortality over 60 days, especially in patients whose BMI is below 25 or above 35 , and increases days without mechanical ventilation. ${ }^{17}$ In another study by Krishnan et al. in 2002 in the US, 1539 patients who were admitted to two separate teaching hospitals and were hospitalized for at least 96 hours in intensive care units were studied. ${ }^{12}$ Disease severity indices were collected by SAPS and nutritional assessment including serum albumin level and BMI. The results indicated that the caloric intake was $50.6 \%$ of the expected ACCP goals. Also, the amount of caloric intake depends on the intestinal intolerance but does not depend on the severity of the disease and the basic nutritional status and type of nutrition. Their study also found that patients with moderate caloric intake had better outcomes than those who received low or high calorie intake. ${ }^{12}$ In a study conducted by the Department of Nutrition and Diet Therapy at Hammersmith Hospital, London, the results showed that precise nutritional assessment and strategies to improve the quantity and quality of diet therapy in patients hospitalized at intensive care units reduce the prevalence of malnutrition, improve weight gain and thus facilitating the healing process becomes successful. ${ }^{18}$ Some studies report like statemnets above ${ }^{19,20}$. Our study is in agreement with all previous cited studies that, by improving the quality and quantity of patients' diets, healing process is facilitated and malnutrition is reduced. The results of the present study show that the gavage solution provided to trauma patients hospitalized at the surgical intensive care unit is insufficient to meet the energy and protein requirements of the patients.

In conclusion, it seems necessary for sensitive patients at high risk, to use precise assessment systems and nutritional support in the hospital by coordinating the medical staff, including doctors, nurses, clinical pharmacists and dietitians.

\section{List of acronyms}

ACCP - American College of Chest Physicians BMI - Body Mass Index

\section{Author's contributions}

All authors played a substantial role in data acquisition and analysis, and also in conception and revision of the manuscript.

\section{Acknowledgments}

No

\section{Funding}

There was no funding support for this study.

\section{Conflict of Interest}

The authors have no conflicts to disclose.

\section{Ethical Publication Statement}

We confirm that we have read the Journal's position on issues involved in ethical publication and affirm that this report is consistent with those guidelines.

\section{Corresponding Author}

Hamid Reza Hemmati, Department of Surgery, Kowsar Hospital, Semnan University of Medical Sciences, Semnan, Iran. Phone:+ 982331422449

ORCID iD: 0000-0002-7631-8176

Email: dr.hemmati2007@yahoo.com

E-mails of co-authors

Babak Hosseinzadeh Zoroufchi: babakhz.anesthesia@gmail.com

ORCID iD: 0000-0003-0624-4025

Abolfazl Abdollahpour: Abolfazlabdollahpoor@semums.ac.ir ORCID iD: 0000-0001-7485-8198

\section{References}

1. Mardani M, Seifi F, Ebrahimzadeh F. Nutritional Assessment of patients at admitted and discharge in orthopedic section of Khorramabad Shohada Ashaier hospital. Yafteh 2014;15:5-12.

2. Raslan M, Gonzalez MC, Dias MCG, et al. Comparison of nutritional risk screening tools for predicting clinical outcomes in hospitalized patients. Nutrition 2010;26:721-6.

3. Aguilar-Nascimento JE, Kudsk KA. Early nutritional therapy: the role of enteral and parenteral routes. Curr Opin Clin Nutr Metab Care 2008;11:255-60. 
4. Dvir D, Cohen J, Singer P. Computerized energy balance and complications in critically ill patients: an observational study. Clin Nutr 2006;25:37-44.

5. Sungurtekin H, Sungurtekin U, Oner O, Okke D. Nutrition Assessment in Critically Ill Patients. Nutrition Clinical Practice 2008;23:635-41.

6. Martins JR, Shiroma GM, Horie LM, et al. Factors leading to discrepancies between prescription and intake of enteral nutrition therapy in hospitalized patients. Nutrition 2012;28:864-7.

7. Giner M, Laviano A, Meguid MM, Gleason JR. In 1995 a correlation between malnutrition and poor outcome in critically ill patients still exists. Nutrition 1996;12:23-9.

8. Marik PE, Zaloga GP. Early enteral nutrition in acutely ill patients: a systematic review. Crit Care Med 2001;29:2264-70.

9. Parrish CR, McCray SF. Nutrition support for the mechanically ventilated patient. Crit Care Nurse 2003;23:77-80.

10. Kruizenga HM, Van Tulder MW, Seidell JC, et al. Effectiveness and cost-effectiveness of early screening and treatment of malnourished patients. Am J Clin Nutr 2005;82:1082-9.

11. Payne-James J, Grimble G, Silk D. Artificial nutrition support in clinical practice, 2nd ed. London: MPG Book; 2001.P.325-329.

12. Krishnan JA, Parce PB, Martinez A, et al. Caloric intake in medical ICU patients: consistency of care with guidelines and relationship to clinical outcomes. Chest 2003;124:297-305.

13. Wyszynski DF, Perman MAC. Prevalence of hospital malnutrition in Argentina: preliminary results of a population-based study. Nutrition 2003;19:115-9.

14. Sheean PM, Peterson SJ, Gurka DP. Nutrition assessment: the reproducibility of subjective global assessment in patients requiring mechanical ventilation. Eur J Clin Nutr 2010;64:1358-64.
15. Fruchtenicht AV, Poziomyck AK, Kabke GB, et al. Nutritional risk assessment in critically ill cancer patients: systematic review. Rev Bras Ter 2015;27:274-83.

16. Wei X, Day AG, Ouellette-Kuntz H, Heyland DK. The Association Between Nutritional Adequacy and Long-Term Outcomes in Critically Ill Patients Requiring Prolonged Mechanical Ventilation: A Multicenter Cohort Study. Crit Care Med 2015;43:1569-79.

17. Alberda C, Gramlich L, Jones N, et al. The relationship between nutritional intake and clinical outcomes in critically ill patients: results of an international multicenter observational study. Intensive Care Med 2009;35:1728-37.

18. OFlynn J, Peake H, Hickson M, et al. The prevalence of malnutrition in hospitals can be reduced: results from three consecutive crosssectional studies. Clin Nutr 2005;24:1078-88.

19. Moghtadaei M, Otoukesh B, Bodduhi B, et al.Evaluation of Patellar Position before and After Medial Opening Wedge High Tibial Osteotomy: Radiographic and Computed Tomography Findings.Med Arch. 2016 ;70:293-5.

20. Yeganeh A, Otoukesh B, Kaghazian P, et al.Evaluation of the Etiologies of Implant Fracture in Patients With Fractures of the Implants of Lower Limbs' Long Bones.Med Arch. 2015;69:405-8.

21. Kashaki M, Samghabadi FM, Bordbar A.Effect of Fortification of Breast Milk in Conjugation with Protein Supplement on Neurodevelopment of Preterm Low Birth Weight Infants at 3 Years.Med Arch. 2019 ;73:344-50.

Submission: October 12, 2019

Acceptance: December 11, 2019 